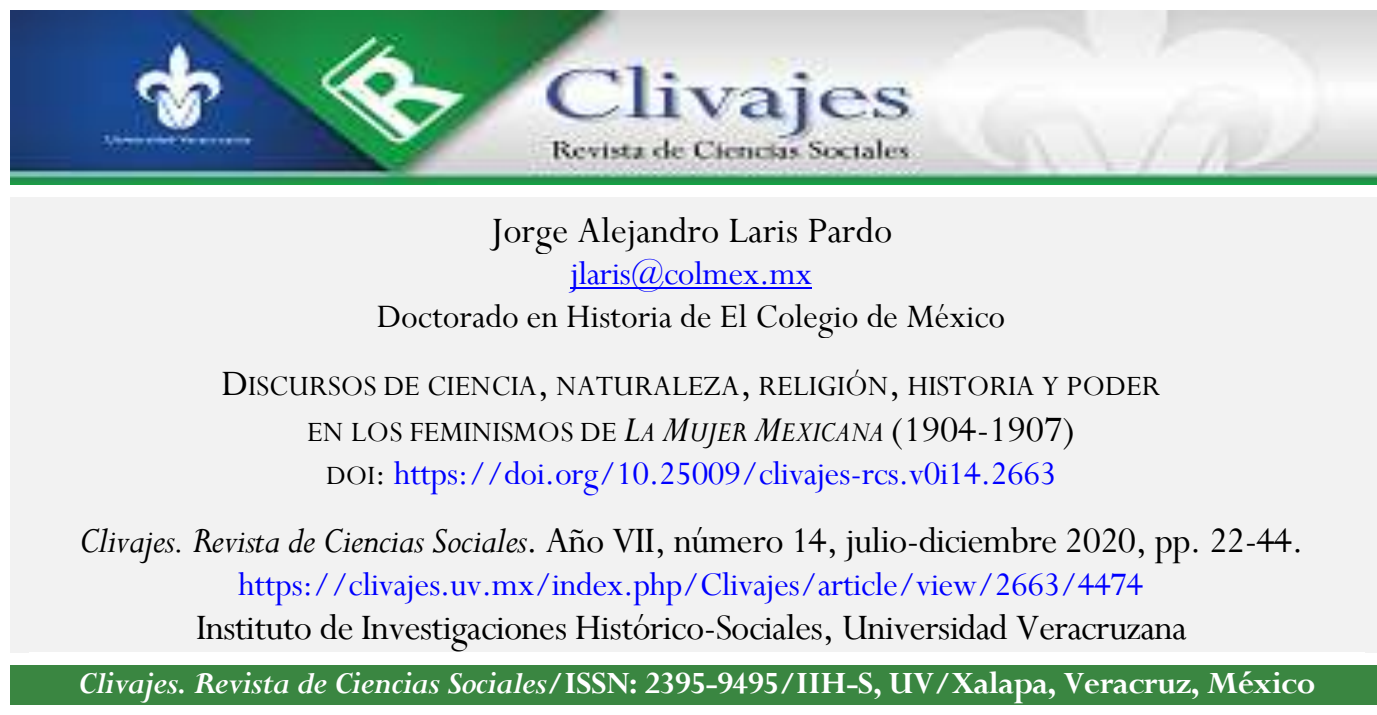

Recibido: 06/01/2020

Aceptado: 20/01/2020

Dictaminado: $16 / 10 / 2020$

Clivajes. Revista de Ciencias Sociales (ISSN: 2395-9495), Año VII, Núm. 14, julio-diciembre, 2020 Instituto de Investigaciones Histórico-Sociales, Universidad Veracruzana, México 


\title{
DISCURSOS DE CIENCIA, NATURALEZA, RELIGIÓN, HISTORIA Y PODER EN LOS FEMINISMOS DE LA MUJER MEXICANA (1904-1907)
}

\author{
Jorge Alejandro Laris Pardo*
}

\section{Resumen}

El propósito de este trabajo es plantear las diversas maneras como las escritoras de la revista feminista La Mujer Mexicana (1904-1907) entendían la relación entre feminidad, naturaleza y búsqueda del conocimiento. En las páginas de esta publicación, distintas autoras expresaron ideas sobre ciencia, religión, historia y poder. A través de este ejercicio de análisis, no sólo se busca contribuir a la comprensión de los feminismos durante el porfiriato, sino hacer patentes las complejidades discursivas con que en la revista en cuestión, entre otras fuentes, se expresó una gama realmente amplia y plural de visiones sobre el papel que las mujeres de entonces debían desempeñar en la sociedad mexicana.
\end{abstract}

Palabras clave: Discurso, Feminismo, Historiografía, Prensa femenina

\section{DiSCOURSES OF SCIENCE, NATURE, RELIGION, HISTORY AND POWER IN THE FEMINISMS OF LA MUJER}

MEXICANA (1904-1907)

\section{Summary}

The purpose of this work is to present the different ways in which the writers of the feminist magazine La Mujer Mexicana (The Mexican Woman) (1904-1907) understood the relationship between femininity, nature and the search for knowledge. In the pages of this publication, different female authors expressed ideas about science, religion, history and power. Through this exercise of analysis, it is not only sought to contribute to the understanding of feminisms during the Porfiriato, but to make patent the discursive complexities with which in the magazine in question, among other sources, a truly wide and plural range of views about the role that women of that time had to perform in Mexican society was expressed.

Keywords: Speech, Feminism, Historiography, Women's press

\author{
DisCoURS DE SCIENCE, NATURE, RELIGION, HISTOIRE ET POUVOIR CHEZ LES FÉMINISMES DE LA MUJER \\ MEXICANA (1904-1907)
}

\section{Résumé}

Le but de ce travail est celui d'exposer les diverses manières à travers lesquelles les écrivaines de la revue féministe La Mujer Mexicana (1904-1907) comprenaient la relation parmi féminité, nature et recherche de la connaissance. Dans les pages de cette publication, diverses auteures ont exprimé des idées sur science, religion, histoire et pouvoir. À travers cet exercice d'analyse, on ne cherche pas seulement à contribuer à la compréhension des féminismes pendant le Porfiriat, mais aussi contribuer au fait de mettre en évidence les complexités discursives avec lesquelles la revue mentionnée a exprimé, entre autres sources, une gamme vraiment grande et plurielle des visions sur le rôle que les femmes d'autrefois devraient jouer dans la société mexicaine.

Mots clés : Discours, Féminisme, Historiographie, Presse féminine

${ }^{*}$ Licenciado en Historia por la Universidad Autónoma de Yucatán, actualmente realiza estudios de Doctorado en Historia en El Colegio de México. Contacto: jlaris@colmex.mx.

Clivajes. Revista de Ciencias Sociales (ISSN: 2395-9495), Año VII, Núm. 14, julio-diciembre, 2020 Instituto de Investigaciones Histórico-Sociales, Universidad Veracruzana, México 


\section{INTRODUCCIÓN}

A principios del siglo XX, hubo en México un grupo de mujeres dispuestas a ir más allá de los roles que la sociedad tradicional occidental esperaba de ellas, y se involucraron en la vida intelectual y pública del país. ${ }^{1}$ Algunas se organizaron para formar la Sociedad Protectora de la Mujer, con el órgano de divulgación La Mujer Mexicana. Revista mensual científico-literaria, consagrada a la evolución y perfeccionamiento de la mujer mexicana. Dirigida, redactada y sostenida sólo por señoras y señoritas (1904-1907).

El propósito de este ensayo es analizar cómo entendían la relación entre feminidad, naturaleza y búsqueda de conocimiento quienes escribían es dicha revista, y cómo a través de esta relación ambicionaban un nuevo discurso que no fuese hostil a su incursión en la esfera intelectual de la época. Desde mi perspectiva, las autoras de La Mujer Mexicana contribuyeron a la discusión sobre la diferencia sexual, basadas en ciertas nociones sobre la ciencia, el arte, la religión y el progreso. Sus ideas fueron sin duda feministas, heterogéneas, y deben ser entendidas en su particular contexto histórico. En este sentido, es posible afirmar que $L a$ Mujer Mexicana fue la primera revista feminista del siglo XX en México.

No obstante, Rosa María Valles Ruiz expresa una idea distinta (2019, pp. 95-99), que reserva el apelativo "feminista" a otra publicación: Mujer Moderna (1915-1919), debido a que la línea editorial de esta última se manifestó más decididamente a favor de la participación política de las mujeres. Hay que decir, sin embargo, que este juicio se sustenta en una visión esencialista del feminismo, que puede llegar a tener efectos restrictivos en el entendimiento del particularismo histórico. Por ello, prefiero optar por una visión más amplia del feminismo o, mejor dicho, de los feminismos. Ultimadamente se trata de una cuestión que no puede ser dirimida de manera concluyente, y depende sobre todo de las decisiones metodológicas con las que nos acercamos al estudio del pasado: la aproximación genitiva, sobre el origen del feminismo actual, o la particularista, acerca de cómo éste se vivió en su tiempo. En este trabajo nos decantamos por la segunda.

En este sentido, asumo la posición de la escuela de Joan W. Scott, que considera a las mujeres agentes activos en la historia intelectual y política. En efecto, si hasta hace unas décadas la historiografía las había omitido de sus narrativas, se debió más a la falta de interés de los historiadores en las acciones e ideas de las agentes históricas, que a la escasez de testimonios. Un imperativo, aquí, es mostrar que los derechos de las mujeres no fueron graciosamente otorgados por magnánimos gobernantes, sino ganados a pulso de polémicas y

${ }^{1}$ Para una síntesis sobre la historia del feminismo en México durante el siglo XX, ver Cano (1996). En el plano intelectual y por largos periodos, las mujeres fueron consideradas incapaces de crear, no así de copiar; escribir les estaba prohibido, sin embargo, en el siglo XIX, cada vez más autoras trataron de ganarse la vida escribiendo (Perrot, 2008, pp. 82-86). 
luchas, con activa participación femenina. Scott (1992) sostiene que su programa tiene como objetivo comprender cómo y por qué cambian las ideas sobre la diferencia social, cómo se imponen las ideologías y cómo tales ideas fijan los límites de la conducta y dictan el significado de la experiencia femenina (pp. 38-65). Este es un programa muy amplio, evidentemente, y lo abordaremos, limitándonos al plano de la historia intelectual y de la prensa.

La Mujer Mexicana fue propiedad de la empresaria cultural Luz Fernández viuda de Herrera, y dirigida sucesivamente por algunas de las mujeres más influyentes del porfiriato en la capital; fundadoras, además, de la Sociedad Protectora de la Mujer. Inicialmente, asumió la dirección la tabasqueña Dolores Correa Zapata (1853-1924), quien por esos años de principios del siglo XX impartía la clase de Deberes y Economía Doméstica en la Escuela Normal de Mujeres de la Ciudad de México (Alvarado, 2015, pp. 54-55); más tarde, el mismo año (1904), la sustituyó Victoria Sandoval de Zarco, primera abogada mexicana (Cano, 2012, p. 15); durante la primera mitad de 1905, se hizo cargo de la revista la mexiquense Laura Méndez de Cuenca (1853-1928), entonces inspectora de escuelas en Xochimilco y luego, en 1906, fundadora del Consejo Supremo de Instrucción Pública (Bazant, 2015, pp. 121-127). Tras ella, la última directora fue la joven tapatía Antonia Leonila Ursúa López (1883-1954), estudiante de Medicina en aquella época y la quinta mujer en cursar la carrera en la Ciudad de México (Rodríguez de Romo \& Castañeda López, 2012, p. 25). Todas ellas continuaron la lucha decimonónica por ganar un lugar digno para las mujeres en la prensa capitalina.

Estudiar la prensa significa desentrañar tanto las formas de expresión de una época, como las exigencias sociales y los puntos de vista de las y los periodistas (Hernández, 2012, p. 5); por ello, no es de extrañar el interés de la historiografía por La Mujer Mexicana. Por un lado, Lorena Mejía Macilla (2016) la ha conceptuado como órgano dirigido a las maestras, lo que la llevó a interesarse en la difusión de ideas pedagógicas en sus páginas; por esta vía, llegó a la conclusión de que, en su momento, la revista promovió una pedagogía muy cercana a la escuela moderna del español Francisco Ferrer Guardia. ${ }^{2}$ Por otro lado, Lucrecia Infante $(2009 ; 2004)$, quien se interesó en la revista a partir de su estudio sobre la evolución histórica de las escritoras mexicanas del siglo XIX, considera que la publicación tuvo un punto de vista feminista: "hasta cierto punto, excesivamente crítico" para la época; ${ }^{3}$ opinión

\footnotetext{
${ }^{2}$ Ferrer Guardia defendía que la educación debía ser integral - esto es, enseñar ciencia mediante la práctica cotidiana, fomentar el libre desarrollo del niño, evitar el aprendizaje memorístico- y libre de dogmas religiosos y nacionalistas. Para más sobre la doctrina de Ferrer Guardia, véase Arteaga Castillo (2005) y Mejía Macilla (2016).

${ }^{3}$ Señala Infante (2009): "es en mi opinión, el impreso que reúne la experiencia empresarial, literaria y cultural de las publicaciones de su género que le antecedieron y, claro, de las escritoras que les dieron vida” (p. 240). Para pensar en lo subversivo de este fenómeno, reflexionemos sobre la enorme diferencia que hay entre la connotación de "hombre público" frente a la de "mujer pública" (Perrot, 2008, pp. 116-117).
} 
que contrasta con la de Marita Martín Orozco (2005), que la juzga menos provocadora que Las violetas del Anáhuac (1887-1889) y refleja el punto de vista de mujeres de la élite, que solían cuestionar mesuradamente las actividades de otras representantes de su género (p. $68)$.

¿Cómo una misma publicación puede dar lugar a lecturas tan dispares como la de Infante y Martín? En mi opinión, el problema es que las autoras han tratado de definir una línea editorial clara para La Mujer Mexicana. Las implicaciones de estos puntos de vista han llamado la atención de Morelos Torres Aguilar y Ruth Yolanda Villegas (2015), quienes observan que en la prensa femenina del porfiriato llegaron a publicarse artículos que apoyaban posturas antagónicas sobre la educación de la mujer (p. 238), es decir, a pesar de que los periódicos decimonónicos fueron concebidos como medios didácticos y de propaganda ideológica, en ocasiones había lugar en ellos para el debate, supeditado a ciertos márgenes.

En el caso de La Mujer Mexicana, el marco ideológico era el feminismo en su sentido más extenso, no así en su diversidad y particularidades. Mi hipótesis es que las voces expresadas en la revista carecían de un contra-discurso coherente, pues en sus páginas se expresaron voces heterogéneas que proponían proyectos distintos. Tal pluralidad de proyectos obedecía y obedece a que el cambio social no sigue una regla teleológica que dicte su dirección. Al contrario, todo momento de cambio es a la vez un tiempo de propuestas, innovación, titubeo y conservadurismo, en el que es imposible determinar a priori cuál será el discurso hegemónico que emergerá victorioso para enfrentar una nueva batalla (Scott, 2008, pp. 114-117). Este es el valor del estudio del particularismo histórico aquí emprendido.

Con esto en mente, en la primera parte de este ensayo planteo los argumentos naturalistas sobre el papel que la mujer debía tener en la sociedad; en la segunda, exploro la relación que las escritoras de La Mujer Mexicana encontraban entre las ciencias y otras ramas del conocimiento y la cultura, pues, a finales del siglo XIX y principios del XX, rara vez se entendía la ciencia desvinculada de otras actividades intelectuales, como el arte; ${ }^{4}$ en la tercera parte, analizo las diferentes concepciones de la relación entre ciencia y religión, lo que conduce a la cuarta parte, donde expongo las concepciones de las autoras sobre la relación entre feminismo, progreso histórico y participación de las mujeres en la ciencia, como medio para adquirir poder en la sociedad, en el más pleno sentido baconiano de conocimiento es poder; finalmente, en la conclusión pondero lo que la diversidad de discursos puede enseñarnos sobre los feminismos en tiempos del porfiriato, y el sentido en que es

\footnotetext{
${ }^{4}$ De hecho, el concepto de "científico" fue propuesto como análogo al de "artista”, en 1840, por el matemático, filósofo y científico William Whewell (Solís \& Sellés, 2013, p. 782). 
posible comprender la convivencia de puntos de vista, a veces antagónicos, en un medio que intentaba transgredir el discurso hegemónico de la época y proponer valores alternativos.

\section{FEMINIDAD Y NATURALISMO}

La ciencia siempre ha tenido como axioma hacer aserciones sobre el mundo natural, y desde tiempos de Platón y Aristóteles, la ciencia occidental ha buscado el orden escondido en el aparente caos de la naturaleza (Elena, 1985, pp. 17-21). Esta visión antecede a la moderna concepción de las leyes de la naturaleza ${ }^{5}$ que se entendieron, durante el siglo XIX, como descripciones de lo inmutable del mundo. En La Mujer Mexicana, Manuela Contreras, quien escribía desde Chilpancingo, creía y expresaba que las leyes naturales eran ineludibles. ${ }^{6}$ A finales del siglo XIX, no había acuerdo sobre el origen y razón de ser de estas leyes: ¿tenían un origen divino?, ¿eran producto de la mente humana?, ¿eran un atributo intrínseco de la naturaleza? De esta última idea era partidaria Luz Valle David, activa periodista del porfiriato. $^{7}$

Pero, si había un componente inmutable en la naturaleza, ¿qué podría ser lo eterno de la diferencia entre sexos? A veces, la diferencia residía en las cualidades morales, Adela López viuda de Herrera, colaboradora recurrente, proclamaba que el talento era masculino y la sabiduría, femenina. En la misma línea encontramos a Trinidad Orcillés, maestra chihuahuense, fundadora en 1892 y directora en 1895 de la Sociedad Filomática de aquel Estado, y periodista feminista, activa en los últimos 20 años del porfiriato. ${ }^{8}$ Estaba convencida de que a la mujer pertenecía en exclusiva la capacidad de cuidar del hogar y educar a las futuras generaciones. ${ }^{9}$ Incluso la ensayista Laureana Wright de Kleinhans guerrerense, que pasó su vida adulta en la Ciudad de México, ávida literata feminista, cuyo prestigio e influencia valieron para que sus artículos se difundieran de manera póstuma en

\footnotetext{
${ }^{5}$ También se ha señalado que la idea de un emperador legislador, en conjunción con la de un dios emperador del universo, contribuyó al fenómeno (Needham, 1977, p. 37).

${ }^{6}$ Así se explicaba su espíritu la inevitabilidad de la muerte: Contreras, M. (1904, mayo). A mi noble maestro. Señor Don Enrique Rébsamen. La Mujer Mexicana, p. 9.

${ }^{7}$ Valle David, L. (1904, julio). Trabajo leído en la velada que en razón del distinguido profesor de gimnasia racional D. Alberto D. Landa tuvo verificativo el 26 de abril de 1904 (primera parte). La Mujer Mexicana, pp. 5-6. Sobre su labor periodística, así aparece en la obra de Infante (2004, p. 260).

${ }^{8}$ Sobre su actividad en Chihuahua, véase Larios Guzmán \& Hernández Orozco (2011). La Sociedad Filomática en Chihuahua, que, según Infante (2009), "público regularmente en revistas como Violetas del Anáhuac, El periódico de las señoras y La Mujer Mexicana (pp. 288, 291, 322).

${ }^{9}$ Orcillés, T. (1906a, abril). La meta de nuestro esfuerzo. La Mujer Mexicana, pp. 3-4. En la década de los noventa del siglo XIX, la autora había publicado también en Violetas del Anáhuac y El Periódico de las Señoras (Infante, 2009, pp. 288, 291 y 322).
} 
La Mujer Mexicana, ${ }^{10}$ y dura crítica de los determinismos biológicos- aseguró que la misión común de la mujer humana, y de todas las especies, era ser el principal eje de la familia. ${ }^{11}$

Para otras escritoras, la diferencia entre hombres y mujeres, más que moral, era física. Balbina González, colaboradora jalisciense, aseguraba, por ejemplo, que el hombre era materialmente superior a la mujer, pero no intelectual ni moralmente. ${ }^{12}$ En realidad, este era un tema a debate. Wright se oponía a la creencia de que la fuerza física de las mujeres era naturalmente inferior a la de los hombres. ${ }^{13}$ No obstante, la mayoría de las autoras creían en la igualdad intelectual entre los sexos. Tal es el caso de otra escritora regular de la revista, María Patiño Pérez, quien explicaba que la mujer no era mala ni perfecta ni tenía que serlo, porque era igual al hombre. ${ }^{14}$ La máxima expresión de esta convicción de equidad se materializó en la fundación de escuelas mixtas, aplaudida con júbilo por Valle David. ${ }^{15}$

La fe en la educación como forjadora de nuevos pueblos, tan característica del pensamiento liberal, se sustentaba en la concepción de que la naturaleza no era fija e inmutable, sino maleable. Noción basada en una definición laxa de la herencia, según la cual cuerpo y personalidad dependían de un número infinito de elementos ambientales que podían variar y combinarse entre sí de diversas maneras con diversos resultados. ${ }^{16}$ Esto permitía a Francisca Escárcega, colaboradora de La Mujer Mexicana, explicar que el carácter cauteloso y sumiso de la mujer no era culpa de la naturaleza, sino de la sociedad, ${ }^{17}$ y hacía temer a Wright que un padre "excéntrico y ridículo" pudiese destruir la inteligencia innata de su hija. ${ }^{18}$ No solo las costumbres o la familia podían causar la ruina de una mujer, sino también la alimentación y la pobreza, como explicaba Josefa Orozco, maestra de la Escuela Normal de Puebla. ${ }^{19}$

Wright fue una de las más grandes defensoras de la idea de la naturaleza maleable. Creía incluso que la atracción sexual estaba condicionada por el ambiente, y criticaba a los hombres que negaban el derecho de las mujeres a estudiar, por miedo a que perdiesen su

\footnotetext{
${ }^{10}$ Sobre ella, véase Infante (2004, pp. 2-6) y 2009 (pp. 240-249).

${ }^{11}$ Wright de Kleinhans, L. (1907b, junio). La mujer perfecta. La Mujer Mexicana, pp. 1-2.

${ }^{12}$ González, B. (1906, julio). La mujer en la actualidad. La Mujer Mexicana, pp. 4-6. Infante (2009) ha encontrado que esta autora nació en Guadalajara, en el año 1863 (p. 264).

13 "La única preponderancia que el hombre efectivamente posee sobre la mujer es la física, y aún esta suele más bien ser efecto del género de vida que sigue, que efecto de su propia conformación”: Wright (1905b, julio). La emancipación de la mujer por medio del estudio (primera parte). La Mujer Mexicana, pp. 1-3.

${ }^{14}$ Patiño Suárez, M. (1904, mayo). Trabajo leído en la sociedad La Elocuencia. La Mujer Mexicana, pp. 1-4.

${ }^{15}$ Valle David (1904, agosto). Trabajo leído en la velada que en razón de distinguido profesor de gimnasia racional D. Alberto D. Landa tuvo verificativo el 26 de abril de 1904 (segunda parte)...

${ }^{16}$ Lo que contrastaba con la posición dura de la herencia o determinista (López Beltrán, 2002, p. 241).

17 “Tal es, en efecto, el carácter de la mujer en general (...) pero no culpemos a la naturaleza”: Escárcega, F. (1904, septiembre). El carácter de la mujer. La Mujer Mexicana, pp. 4-5.

${ }^{18}$ Wright (1906a, enero). La mujer contraproducente. La Mujer Mexicana, pp. 1-3.

${ }^{19}$ Orozco, J. (1905, enero). Memoria (primera parte). La Mujer Mexicana, pp. 6-9. 
atractivo al portar un instrumento quirúrgico o un libro de leyes, o bien acudir a un observatorio y trabajar en un laboratorio de química. A ello respondía Wright: "cuando esto suceda, el hombre volverá a robustecer poco a poco su ilusión, y la mujer científica no le causará peor impresión que la nodriza, la costurera y la cocinera actuales". ${ }^{20}$ Cabe destacar que, al parecer, Wright aplicaba esta flexibilidad sólo a las relaciones heterosexuales, pues en otra ocasión afirmó que el hombre era el compañero natural de la mujer. ${ }^{21}$ Además, para esta autora, aun cuando la mujer era madre por naturaleza, moralmente estaba obligada a ir más allá, sí quería salir del reino natural y entrar de lleno a la civilización. ${ }^{22}$ En el pensamiento liberal del que era parte, la naturaleza podía cambiarse y lo natural no era necesariamente deseable. Por eso, explicaba a sus lectoras que tenían el deber de modificar las tiernas naturalezas de sus hijos. ${ }^{23}$

Curiosamente, había un aspecto de lo femenino al que estas escritoras no parecían dispuestas a renunciar. Aquello fue descrito por la también colaboradora Ángela Serrano y Ortiz como "un regalo de la naturaleza", del cual Wright pensaba que la mujer era representante natural sobre la tierra: la hermosura. ${ }^{24}$ Me parece que, al menos en parte, esta actitud constituyó una estrategia para defender el ingreso de las mujeres en la cultura del arte. El silogismo era que sólo lo hermoso podía producir verdadera hermosura, de manera que sólo la mujer podía crear verdadero arte. ${ }^{25}$ Así lo explicaba un artículo de la redacción:

El cultivo de la poesía enaltece el espíritu; fortalece el ánimo, afina y pule los sentimientos, arraiga el culto por lo bello y lo grande, y abre nuevos horizontes para encontrar resignación, consuelo y aliento en la lucha por la existencia.

Y si es tan noble en el hombre, en la mujer es además sagrado y bienhechor, porque la convierte en mensajera de la ternura escrita. Nadie como ella puede traducir los estremecimientos misteriosos que sacan las lágrimas a los ojos y los suspiros al pecho, cuando el amor, como principal agente, la obliga a mover el pensamiento y la pluma. ${ }^{26}$

\footnotetext{
${ }^{20}$ Wright (1905d, septiembre). La emancipación de la mujer... (tercera parte)..., pp. 1-3.

${ }^{21}$ Wright (1905f, noviembre). La mujer contemporánea (primera parte). La Mujer Mexicana, pp. 1-3.

${ }^{22}$ Wright (1907b, junio). La mujer perfecta..., pp. 1-2.

${ }^{23}$ Wright (1905g, diciembre). La mujer contemporánea (segunda parte)..., pp. 1-3.

${ }^{24}$ Serrano y Ortiz, A. (1904, marzo). Pensamientos de una moralista. La Mujer Mexicana, pp. 4-5; Wright (1906d, abril). La mujer coqueta..., pp. 1-2.

${ }^{25}$ Este razonamiento recuerda al feminismo cultural que, según Londa Schiebinger (2004), surgió a mediados del siglo XIX. Promovía (y promueve) la revaloración positiva de ciertas prácticas consideradas femeninas, y su adopción, como tales, en la moral social. El riesgo de esta posición es que roza el esencialismo y puede ser aprovechada por los movimientos conservadores (pp. 394-397).

${ }^{26}$ Anónimo [lo atribuyo a las editoras] (1906, mayo). Josefina Pérez García Torres. La Mujer Mexicana, p. 1.
} 
En 1881, el campechano Pablo García Montilla (1824-1893) explicó que la grandeza de la civilización se manifestaba en las ventajas que traía a la humanidad la cultura de las ciencias y de las artes. Una nueva forma de civilización, que proporcionaba conservación del ser, alivio de las dolencias, desarrollo de las facultades intelectuales y morales, y los goces de la vida social. ${ }^{27}$ Esta era la expresión de un sentir común sobre la cultura afrancesada de la época, popularizado en los trabajos de Henri de Saint-Simon (1760-1825), August Comte (17981957) y Pierre-Joseph Proudhon (1809-1965) (Kohn-Bramstedt, 1961, p. 185); de suerte que la gente ilustrada de aquella época no distinguía tajantemente entre el quehacer científico y el artístico.

Así se comprende la descripción de Valle David sobre la alegría del mundo: "es la música para el espíritu de Mozart, es la poesía para el alma de Víctor Hugo, es el Razonamiento para la conciencia de Spencer y es la manifestación de la inteligencia para el ilustre Edison". ${ }^{28}$ Una alegoría en donde la felicidad estaba ligada a artistas y científicos por igual. También entendemos por qué la Sociedad Protectora de la Mujer tenía como prioridad "formar una colectividad en donde se cultivasen la literatura, las artes, y se hiciese que las mujeres se alzasen a las bóvedas del templo de la virtud y de la ciencia”. ${ }^{29}$ Congruente con ello, una velada cultural en la Escuela Normal de Profesoras podía incluir un recital de piano, una disertación sobre la teoría del calor, una sesión de cantos y otra conferencia sobre el orden en que se desarrollaban las facultades del alma en la vida diaria. ${ }^{30}$

Entonces era, pues, necesario hacer partícipe a la mujer de la cultura, las ciencias y las artes, actividades de las que las autoras de La Mujer Mexicana se sentían excluidas; por eso, Wright condenaba a científicos como Hipócrates y Galeno, quienes, a su juicio, examinaron "el organismo femenino, y no tuvieron por conveniente darle cuenta de su examen, así como el químico, el físico, el astrónomo y el geólogo no tuvieron motivo para introducirla en el santuario de su saber"; la escritora también dirigía sus críticas a artistas como Ariosto, Dante y Petrarca quienes "pudieron cantar las esperanzas, los ensueños y los idilios que ella les inspiraba a cada paso, sin creerse por esto obligados a prestarle su lista para que ella contase los suyos”. ${ }^{31}$ En su opinión, científicos y artistas eran culpables de la marginación de la mujer.

\footnotetext{
${ }^{27}$ Todo esto en un mundo positivo y moderno, en el que la fe religiosa debía desaparecer. García Montilla, P. (1882, enero 29). El catolicismo y la cultura de las ciencias y las artes. El Libre Examen. México.

${ }^{28}$ Valle David (1904, julio). Trabajo leído en la velada que... tuvo verificativo el 26 de abril... (primera parte)...

${ }^{29}$ Bolaños Torres, L. S. (1904, marzo). Alocución pronunciada en la primera sesión de la Sociedad Feminista. La Mujer Mexicana, p. 1.

${ }^{30}$ Conferencias en la Escuela Normal para Profesoras. La Mujer Mexicana, julio de 1904, p. 10.

${ }^{31}$ Wright (1905c, agosto). La emancipación de la mujer... (segunda parte)... 
Quizá este tipo de declaraciones llevó a la historiadora Lucrecia Infante (2009) a alabar en la pluma de Laureana Wright "el desprecio de los argumentos con que la ciencia y la filosofía establecían la inferioridad intelectual de las mujeres” (p. 247), pero, a partir de la lectura de los textos de Wright, discrepo de su interpretación. Si bien, como hemos visto, Wright criticó fuertemente a aquellos que habían excluido a la mujer de las ciencias y de las artes, esto no quiere decir que criticase a la ciencia y a la filosofía en abstracto, sino a personas específicas que las practicaban. Después de todo, ella no vivió en la posmodernidad. Nunca conoció, ni pudo conocer, los horrores del holocausto, de la bomba nuclear, del deterioro ambiental ni del calentamiento global. Lo que latía en su interior era un corazón ilustrado.

Tengo presente el espiritismo de Wright, ${ }^{32}$ pero éste no negaba a la ciencia, sino que la hacía suya. El mismo fundador del espiritismo, Allan Kardec (1804-1869), precisó que su doctrina era una ciencia y no una religión (Kardec, 2008, pp. 24-25) y, en Mérida, el periódico espiritista dirigido por dos reconocidos médicos de la Escuela de Medicina y Farmacia, declaró que algún día la ciencia conocería la naturaleza íntima de los fluidos oculta todavía a sus miradas, descubriría las leyes que regían la comunicación del mundo espiritual con el de los encarnados y proclamaría el definitivo triunfo del espiritismo. ${ }^{33}$ Para Wright, la ciencia era una fuente de placeres y de alegría, al igual que el arte, de allí la gravedad de excluir de su práctica a la mitad de la humanidad.

¡Pobre mujer! (...) A ti no se te ha enseñado, para que lo resguardes mejor, cómo está formado tu cuerpo ni qué substancias son nocivas o benéficas a tu naturaleza (...) A ti no se te ha concedido saber de qué se compone el aire que respiras; qué significa el cielo que te cubre; cuáles son las propiedades del globo que habitas, ni cuáles las leyes que rigen la sociedad en que vives. A ti no se te ha permitido nutrir tu alma, como ninguna combativa, con la savia potente de la instrucción que fortalece y sostiene alimentar las largas veladas de tus cualidades maternales con el estudio de los fenómenos naturales que pudieran dar explicación a tus excepcionales situaciones, ni entretener las penosas vigilias de tu enfermedad con la contemplación grandiosa de lo infinito, que levantando el espíritu de la prosa de la materia, lo hace flotar, purificad y risueño, por los azules espacios sidéreos. No, tú no has podido gozar con estos placeres espirituales, porque tu deber ha sido ignorar hasta los más elementales conocimientos del mundo exterior, ya sean físicos, filosóficos o astronómicos, y no has podido clasificar ni el rayo de luna que penetra por la estrecha ventana de tu alcoba. ${ }^{34}$

\footnotetext{
${ }^{32}$ Sobre el espiritismo de Wright, véase Infante (2004).

${ }^{33}$ Fin del año de 1878. La ley de amor. Periódico del Círculo Espirita "Peralta", 1 de enero de 1875, pp. 191-192

${ }^{34}$ Wright (1905c, agosto). La emancipación de la mujer... (segunda parte)...
} 
Para hacerse parte de la cultura de las ciencias y de las artes, era necesario construir símbolos. Uno de ellos fue la figura mitológica de Minerva, diosa griega de la sabiduría y las artes; alegoría usada por autoras como Dolores Sotomayor, ${ }^{35}$ María Solán ${ }^{36}$ y Adela López Viuda de Herrera, para quien Minerva era la guardiana del templo de la ciencia en México, la que abrió las puertas de la Escuela Nacional Preparatoria para que la mujer calmara su sed intelectual "en las cristalinas aguas de la fuente de la sabiduría y el arte" ${ }^{37}$

Importa decir, sin embargo, que para la construcción de símbolos no hacía falta recurrir a personajes míticos. La Mujer Mexicana dedicó varias de sus primeras planas, sobre todo durante su primer año, a mujeres ilustres. Incluso, en agosto de 1907, le dedicó todo un tomo a Matilde Montoya, primera medica mexicana, que cumplía 20 años de haberse titulado. ${ }^{38}$ El propósito de esta sección era dar suficientes ejemplos reales para convencer a propios y a extraños de que tanto la labor del "artista sublime" como la del "sabio naturalista" estaban a su alcance, de que sólo la instrucción defectuosa las apartaba de su consecución. ${ }^{39}$ Recurrir a símbolos femeninos de carne y hueso fue una innovación discursiva del feminismo de aquella época, y en el que participó activamente Wright, destacando a las escritoras y profesionistas del México de su tiempo y enalteciendo los avances de sus compatriotas en diversos campos de la actividad humana (Alvarado, 2016, p. 26).

Ahora bien, si esto era evidente para la mayoría de las redactoras, eso no significa que lo fuese para la mayoría de la población. Wright se quejaba de las mujeres no feministas que llamaban bachilleras a las profesoras y marimachos a las científicas. ${ }^{40} \mathrm{Al}$ respecto, resulta revelador que, en un trabajo presentado ante sus profesores de medicina, Antonia Ursúa tuviese que pedir disculpas por sus posibles fallas en razón de su sexo: "Para terminar, me permito hacer la sincera manifestación de que abrigo la convicción intima de la humildad de mi trabajo: y cúlpese, como dije, a dos factores: a lo escabroso del asunto y a la incompetencia aún reducida del cerebro femenino". ${ }^{41}$ No sé si Ursúa creía en verdad estas palabras, pero sospecho que era más bien una estrategia retórica para no despertar la cólera celosa de sus calificadores. Esto último explicaría el poema que le dedicó la poeta Novera Aróstegui:

${ }^{35}$ Sotomayor, D. (1904, marzo). Trabajo y ciencia. Cuadro plástico en dos partes (primera parte). La Mujer Mexicana, pp. 5-10.

${ }^{36}$ Solán, M. (1904, junio). Homenaje a la naturaleza y a la ciencia. La Mujer Mexicana, p. 5.

${ }^{37}$ López vda. de Herrera, A. (1904, abril). Ligeros apuntes sobre el feminismo en México. Dedicados a la patria y a las feministas mexicanas. La Mujer Mexicana, pp. 1-2.

${ }^{38}$ Ursúa, A. (1907b, agosto). 25 de agosto. La Mujer Mexicana, p. 1.

${ }^{39}$ La Redacción. (1904, enero). Memoria. La Mujer Mexicana. p. 1.

${ }^{40}$ Wright (1906b, enero). La mujer presuntuosa. La Mujer Mexicana, pp. 1-2.

${ }^{41}$ Ursúa (1905, febrero). Vida, salud y enfermedad. Trabajo leído por su autora en la clase de procesos morbosos generales de la Escuela Nacional de Medicina (segunda parte). La Mujer Mexicana, pp. 2-5. 
Si el hombre vivo te trató cruelmente,

Es en verdad muy noble tu revancha:

Viéndolo muerto - cuando ya no siente-

Destrozar sus entrañas en la plancha. ${ }^{42}$

Por otro lado, había feministas de un corte más tradicionalista que, si bien reconocían la capacidad intelectual de las mujeres para dedicarse a la ciencia y a los estudios, no veían con mucho agrado que se dedicasen a la ciencia. Tal es el caso de Trinidad Orcillés, quien escribió:

Dejemos los grandes problemas de la radioterapia, de la telefonía sin hilos; los intrincados laberintos de la abogacía y de la banca; los portentos costosísimos del arte y de las industrias, como conquistas del sexo fuerte; y nosotras, las firmes, las resueltas, las perseverantes, las sentidas, busquemos en terreno moral, la producción más rica y exquisita que va perdiendo la humanidad más cada día, por una equivocación incuestionablemente triste. ${ }^{43}$

Orcillés creía que el ingreso de las mujeres a la vida laboral debía de hacerse a través de profesiones más acordes con las ideas de su época sobre la diferencia sexual, fundadas en la noción de complementariedad, según la cual las actitudes modernas (como la ciencia) debían de ser dejadas a los varones, mientras las tradicionales (como la educación y el cuidado de la moral) debían delegarse a las mujeres. ${ }^{44}$ Defendía ella que la mejor carrera para una dama, gracias a las cualidades maternales que supuestamente requería, era el magisterio. Su idiosincrasia era compartida por gran parte de la sociedad; no es gratuito que el porcentaje de profesoras aumentara enormemente durante el porfiriato, a medida que la sociedad feminizaba dicha profesión (Cano, 2000, pp. 207-210).

El contraste entre las ideas de Orcillés y las de Ursúa es un notable ejemplo de la diversidad de discursos feministas que encontramos en La Mujer Mexicana. Esto no implica que la redacción no tuviese sus sesgos. Es evidente que Antonia Ursúa, como directora de la revista, prefería colocar los artículos de Orcillés en las páginas traseras, y en primera plana los de escritoras como Wright. Es posible que la diferencia entre las posturas intelectuales de estas escritoras tuviera un fundamento religioso. En palabras de Wright, también hay poesía en dejarse tentar por el diablo. ${ }^{45}$

\footnotetext{
${ }^{42}$ Aróstegui, N. (1905b, junio). A mi estimada amiga la señorita Antonina L. Ursúa. La Mujer Mexicana, pp. 3.

${ }^{43}$ Orcillés (1906a, abril). La meta de nuestro esfuerzo...

44 "En una era científica las mujeres habían de ser religiosas; en una era secular habían de ser guardianes de la moral" (Schiebinger, 2004, p. 392).

${ }^{45}$ Wright (1906e, mayo). La mujer fanática. La Mujer Mexicana, pp. 3-4. 


\section{CienCIA Y RELIGIÓN EN LA MUJER MEXICANA}

Concepción Gimeno de Flaquer, madrileña de origen que vivió muchos años en México y participó en numerosas revistas de mujeres, ${ }^{46}$ afirmaba que la feminista mexicana era eminentemente católica; que en México había muchas feministas, pero no impías que conociesen la enfermedad del ateísmo, como le llamó. ${ }^{47}$ Una rotunda aserción, posiblemente falsa, que buscaba evitar -sospecho-que la población se enajenara con el feminismo (del cual huiría, si lo juzgaba impío). En La Mujer Mexicana hubo, de hecho, visiones encontradas sobre la religión. Algunas, como la de Dolores Sotomayor, maestra y colaboradora, se mostraban bastante tolerantes en lo respectivo a la fe. Sotomayor explicaba que en Asia habían nacido las tres religiones que consideraba más importantes: el judaísmo, el cristianismo y el islam, sin mostrarse particularmente en favor de ninguna. ${ }^{48}$ Otras, como Laureana Wright, no parecían tan abiertas a la tolerancia de cultos.

Espiritista y liberal, Wright compartía el anticlericalismo que caracterizó al liberalismo mexicano del siglo XIX y que continuó existiendo hasta causar la Guerra Cristera de los años veinte. Criticó con severidad la educación conventual, por considerar que criaba a las mujeres para el matrimonio y para el entretenimiento de otros: la mujer como instrumento. ${ }^{49}$ En una de sus entregas, señaló que la educación religiosa era la agresora de innumerables víctimas, y le dedicó estas palabras a una mujer cuyo nombre no menciona: "una de esas idiotas que hacen de la religión una costumbre inconsciente, única ocupación de su vida, y que no llegan a sentir jamás ni las pasiones del corazón, ni los afectos de la familia, ni los deberes de humanidad". ${ }^{50}$

La misma Antonia Ursúa daba muestras de una arraigada visión materialista del mundo. Idea según la cual tanto el mundo orgánico como el inorgánico poseían los mismos componentes - sólo diferían en su modo de agregación- y las leyes que regían el mundo mineral eran las mismas para animales y vegetales. En consecuencia, criticó abiertamente el vitalismo, noción que había reinado en la medicina decimonónica y según la cual la materia viva tenía una composición y un comportamiento esencialmente distintos de la inerte. ${ }^{51}$ El materialismo atentó contra la idea, fundamental para el credo católico (como

\footnotetext{
${ }^{46}$ Escritora activa desde la década de los setenta en publicaciones como Diario del hogar, Álbum de la mujer (que poseyó), El correo de las señoras, El periódico de las señoras, La Mujer Mexicana y El federalista (Infante, 2009, pp. 112, 162-171, 206-213, 244, 359-365).

${ }^{47}$ Gimeno de Flaquer, C. (1904, julio). La mujer mexicana. La Mujer Mexicana, pp. 1-2.

${ }^{48}$ Sotomayor, D. (1904, abril 2). Trabajo y ciencia (segunda parte). La Mujer Mexicana, 1(3), pp. 5-7.

${ }^{49}$ Wright (1906f, septiembre). La mujer frívola. La Mujer Mexicana.

${ }^{50}$ Wright (1906e, mayo). La mujer fanática...

${ }^{51}$ Sobre el vitalismo en México, véase Viesca \& Sanfilippo (2009, p. 80). 
había dejado en claro la Constitución Dogmática de 1870), ${ }^{52}$ de que el universo tenía un principio al proclamar su existencia eterna. Sin embargo, para Ursúa, la vida tenía su principio en la materia, y ésta, un posible origen inmemorial: "No podemos remontarnos al origen de la vida, a su causa primera, porque sería preciso buscar lo mismo en la materia y ésta, puesto que no puede tenerla, tampoco pudo haber sido creada". ${ }^{53}$

No sabemos cuántas escritoras y lectoras compartieron esta visión materialista del mundo, pero la filosofía positivista promovía la idea de una realidad que escapaba absolutamente de la capacidad humana de conocer. Así, la ciencia quedaba condenada solamente a estudiar el mundo fenoménico o de las experiencias mentales a través de la percepción. ${ }^{54}$ En el siglo XIX, hubo personas que optaron por el materialismo como filosofía de vida; hubo también quienes prefirieron el escepticismo, y sin duda las que se ampararon en esta división epistémica del mundo para tratar de conciliar su fe y su ciencia. En La Mujer Mexicana se publicó un poema de la literata española Amelia Domingo, que expresa muy bien esta división. La poeta explicaba que cuando el equilibrio del cuerpo se rompía, la materia se disgregaba, desorganizaba y volvía a la tierra, muriendo, pero distinguía este fenómeno, "la quietud absoluta aparente", de su convicción personal, al asegurar que creía en la vida tras la muerte. ${ }^{55}$

En la revista también convivieron voces profundamente católicas, como la de Trinidad Orcillés, quien juzgaba que el quehacer de muchas mujeres era una vulgar tendencia y un tributo a la exterioridad, y condenaba a las propias feministas, entre las que se incluía, con las siguientes palabras: "irreligiosas de raíz, el hogar y la patria y la humanidad nos salen importando un bledo". 56 Además, sentenciaba rotundamente que el conocimiento científico jamás podía dar lugar a saberes morales ${ }^{57}$ y que la ciencia en sí misma solamente era audacia, pretensión y embrollo, si no contaba con un timón moral: ${ }^{58}$ objeciones muy cercanas a la postura oficial de la Iglesia Católica. ${ }^{59}$

\footnotetext{
${ }^{52}$ Constitución Dogmática, "Filus-Dei” sobre La Fe Católica, salida de la tercera sesión del Concilio Vaticano I, el 24 de abril de 1870. Recuperado de https: / /bit.ly/2PjrFPG.

${ }^{53}$ Ursúa (1904, octubre). Vida, salud y enfermedad... (primera parte). La Mujer Mexicana, p. 5. Su crítica al vitalismo continúa en la segunda parte de su hermoso ensayo (1905, febrero, pp. 2-5).

${ }^{54}$ Comte (1875) había organizado las ciencias con base en la clasificación de los fenómenos que se presentaban a la experiencia (p. 67).

${ }^{55}$ Domingo S., A. (1906, agosto). Mateana Murguía de Aveleyra. La Mujer Mexicana, pp. 7-8.

${ }^{56}$ Orcillés (1906b, septiembre). ¿Por qué obramos desunidas? La Mujer Mexicana, pp. 3-4.

${ }^{57}$ Orcillés (1907b, febrero). El civismo escolar asesinado por la época. La Mujer Mexicana.

${ }^{58}$ Orcillés (1907c, junio). La mujer en su esfera. La Mujer Mexicana, pp. 3-4.

${ }^{59}$ La Institución había publicado, en 1864, un índice en el que enumeró los principales errores del siglo, siendo uno de ellos el considerar que la "razón humana es el único juez de lo verdadero y de lo falso, del bien y del mal, con absoluta independencia de Dios; es la ley de sí misma, y le bastan sus solas fuerzas naturales para procurar el bien de los hombres y de los pueblos". Índice de los principales errores de nuestro siglo, Syllabus complectens praecipuos nostrae aetatis errores, notados en las Alocuciones Consistoriales y otras Letras Apostólicas de Nuestro Santísimo Padre Pío IX, 8 de diciembre de 1864. Recuperado de https: / / bit.ly/2NGDUp8.
} 
Una visión que contrasta radicalmente con la de Antonia Ursúa, quien subordinaba toda religión a la "ciencia de ciencias", que para ella era la moral, a la cual, afirmó, todos los conocimientos y todas las energías debían subordinarse. Sentenció explícitamente al culto católico, por mantener secuestrado a infinitos seres y volverlos "infecundos, holgazanes y degenerados”. ${ }^{60}$ Con estas palabras, aseguró que la Iglesia estaba cometiendo un pecado mortal y reclamó para la ciencia un privilegio que, hasta el siglo XVIII, había sido exclusivo de la religión, el de dirimir lo que era o no malo. En su discurso, la ciencia se erige como una nueva religión, capaz de juzgar a la antigua; de hecho, no fueron pocas las analogías que se hicieron entonces entre ciencia y religión.

En el mundo social, hay propiedades que indican que tal o cual miembro de cierta institución es competente y digno de confianza para opinar e informar sobre algunos temas (Fricker, 1998, pp. 159-177). En los albores del siglo Xx mexicano, la antigua autoridad de la Iglesia competía de lleno con la nueva autoridad basada en el conocimiento científico. Un fenómeno común en países occidentales: los más importantes historiadores de la ciencia de finales del siglo XIX plantearon su reconstrucción en torno a las relaciones conflictivas entre ciencia y religión. Me refiero a John Dampier (2008 [1875]) y Andrew White (2009 [1896]).

No es de extrañar, pues, que los partidarios de la ciencia, como nueva autoridad, buscaran apropiarse, a través de metáforas, de algunas de las propiedades indicadoras de la iglesia en tanto autoridad. Los ejemplos en este sentido son numerosos; comparto los más elocuentes: Laura Méndez de la Cuenca ponía en la ciencia palabras de Jesús y cualidades amorosas atribuidas a María: "la profunda ciencia, señora del presente siglo, madre amorosa de las generaciones venideras, muestra sus aparatos e instrumentos portentosos con que se arma para aportar a la humanidad del sepulturero prematuro y decirle en el borde de la tumba: 'Lázaro, levántate y anda"”. ${ }^{61}$ La comparación entre la ciencia y la virgen católica fue total en María Solán, quien dedicó a la primera el siguiente verso:

Eres modesta y sencilla

Tu verdad es sacrosanta, Y tu virtud sin mancilla Sobre el cielo se levanta. ${ }^{62}$

La necesidad de presentar a la ciencia como la nueva autoridad, que sustituiría a la Iglesia, se ve reflejada en la actividad didáctica de Dolores Sotomayor. Así, en una obra

\footnotetext{
${ }^{60}$ Ursúa (1907a, enero). Una cuestión. La Mujer Mexicana, pp. 3-4.

${ }^{61}$ Méndez de Cuenca, L. (1907, noviembre). La Exposición de Higiene en Berlín. La Mujer Mexicana, pp. 3-4

${ }^{62}$ Solán (1904, junio). Homenaje a la naturaleza y a la ciencia...
} 
infantil de su autoría observamos que la ciencia aparece ante un alquimista y le ofrece la verdad, incluso antes de presentarse a sí misma, pero a cambio de amor y sumisión incondicional. ${ }^{63}$

Ahora bien, no todas las escritoras compartían esta voluntad de presentar a la ciencia como un ente todopoderoso al que debía de jurársele veneración. Josefa Orozco, de la Escuela Normal de Puebla, advirtió, en su momento, que las opiniones, los deseos y la autoridad influían notablemente sobre nuestros sentidos: "sabemos de antemano que una orquesta es magnífica, y aunque tengamos, como dice un filósofo, un tímpano más duro que un tambor, nos hacemos la ilusión de creer que hemos percibido perfectamente la melodía”, y, por lo tanto, defendió la idea de que había que evitar la enseñanza dogmática: el niño debía de aprender a pensar, a buscar y a descubrir por sí mismo. ${ }^{64}$ He aquí la influencia de la pedagogía moderna que detectó en la revista la historiadora Lorena Mejía (2016). En efecto, otra maestra poblana, Virginia Cabrera, consideraba que la enseñanza tradicional volvía a los niños sumisos ante la autoridad y había sumergido a la humanidad en las tinieblas de la Edad Media. ${ }^{65}$ Pero esta representación de la historia, que la dividía en épocas de sombras y luz, tampoco era la única en la revista.

\section{HISTORIA, CIENCIA, PROGRESO Y FEMINISMO}

Es necesario considerar la visión del progreso histórico y la representación de la mujer en la historia, porque estos discursos nos ayudan a comprender los distintos proyectos feministas presentes en la revista. El de María Patiño Suárez, de corte más tradicional, juzgaba que la Edad Media había sido una época de hechos gloriosos y adelantos en todas las ramas para la humanidad, incluso que "sólo el culto a la mujer y las cruzadas" eran motivos suficientes para merecerle la gratitud de futuras generaciones. ${ }^{66}$ La consecuencia de tal aserción era considerar el medievo como la época en que la mujer tuvo un papel distinguido en la sociedad, lo que proyectaba un ideal según el cual la mujer debía ser objeto de tratos caballerosos y galantería, y la cultura regirse por valores católicos; una visión compartida por Orcillés, quien juzgaba que las naciones, en su avance material, habían ahogado y extinguido para siempre sus virtudes civiles y domésticas, y pisoteado su moralidad y elevados

\footnotetext{
${ }^{63}$ Sotomayor (1904, marzo). Trabajo y ciencia...

${ }^{64}$ Orozco (1904, febrero). Educación de la memoria. Concluye. La Mujer Mexicana, pp. 6-9.

${ }^{65}$ Cabrera, V. (1905, diciembre). Influencias del temor y el amor en la educación intelectual de los niños. La Mujer Mexicana, pp. 4-7.

${ }^{66}$ Patiño Suárez (1904, mayo). Trabajo leído en la sociedad La Elocuencia...
} 
principios para engendrar una generación de alcohólicos y suicidas. ${ }^{67}$ No sorprende que la autora hable de suicidas; tanto los católicos conservadores como los liberales no positivistas solían acusar al positivismo de provocar el suicidio de los jóvenes (Valencia Flores, 2013, p. 53). El progreso, pues, era para ella un mito. A la sociedad moral había que buscarla en el pasado.

Es curioso que las feministas más católicas de la revista aparezcan oponiéndose a la idea del progreso, dado que la concepción apocalíptica, según la cual la historia se divide en dos grandes etapas o momentos, había surgido en occidente y en el seno del cristianismo. Casi como paradoja, las liberales, creyentes o no, eran herederas de esa concepción del pasado y dividían la historia en una época de tinieblas eclesiásticas y un futuro de ilustración positiva. ${ }^{68}$ De ahí que, para Gimeno de Flaquer, la llamada galantería medieval fuese un sofisma. Según ella, el señor feudal permitía al trovador enaltecer a la mujer para que esta no se diese cuenta de su esclavitud. En contraste, todas las prerrogativas modernas se las debía el sexo femenino al hombre moderno, feminista, campeón de la justicia, acaudillador de legiones y denostado luchador, que no peleaba por una mujer, sino por su causa entera. ${ }^{69}$ Idea que compartían autoras como Virginia Cabrera, ${ }^{70}$ Balbina González $^{71}$ y Laureana Wright. ${ }^{72}$

En cuanto a las razones que explicaban el surgimiento del feminismo, congruente con su posición católica, Patiño creía que eran la legislación, cuando estaba debidamente basada en la religión, y la opinión. ${ }^{73}$ María Solán, por lo contrario, daba a la ciencia el papel de liberadora:

El alma femenil siente, se agita

De las tinieblas a la luz se lanza...

"No más esclavitud" la ciencia grita

Y en pos de la verdad resuelta avanza (...)

¡Ciencia infalible tu poder admiro!

¡Nuestra vieja cadena ya está rota!

Llena de gratitud en ti inspiro...

¡Toma esta flor que del alma brota! ${ }^{74}$

${ }^{67}$ Orcillés (1906b, septiembre). ¿Por qué obramos desunidas?; (1907d, diciembre). Utopías ventajosas. La Mujer Mexicana.

${ }^{68}$ Para detalles sobre estas visiones de la historia, Collingwood (2011, pp. 115-116, 143-149).

${ }^{69}$ Gimeno de Flaquer (1904, octubre). Feminismo. Memoria presentada a la Unión Ibero Americana referente al proyecto de una Universidad Femenina. La Mujer Mexicana, pp. 1-2.

${ }^{70}$ Cabrera (1905, diciembre). Influencias del temor y el amor en la educación intelectual de los niños...

${ }^{71}$ González, B. (1906, julio). La mujer en la actualidad...

${ }^{72}$ En múltiples escritos. Véase, por ejemplo, Wright (1905f, noviembre). La mujer contemporánea (primera parte)...

\footnotetext{
${ }^{73}$ Patiño Suárez (1904, mayo). Trabajo. Leído en la sociedad La Elocuencia...

${ }^{74}$ Solán (1904, junio). Homenaje a la naturaleza y a la ciencia...
} 
Con estas palabras, desde el liberalismo se amalgamaban feminismo y progreso ("sin la mujer no puede haber progreso"), ${ }^{75}$ al avance del conocimiento. Visión compartida por Wright, quien exclamaba que para poder llamarnos seres civilizados necesitábamos saber. ${ }^{76}$

¿Era entonces la ciencia, productora de conocimiento, responsable del progreso? Wright duda al respecto; por un lado, afirmaba que el varón, al ser empujado por el impulso irresistible del progreso, había ido, sin proponérselo, arrastrando consigo "a la mitad indispensable y gemela de su especie" - como si el éxito del feminismo estuviese atado a una fuerza suprahistórica-, pero, por otro, cuando se preguntaba quién podría liberar a la mujer, se contestaba a sí misma que nadie, a no ser ella misma. ${ }^{77}$ Se le daba más peso a la agencia que al destino. Eran las palpitaciones de su corazón ilustrado que deseaba creer que el progreso era cosa asegurada, inevitable en el futuro próximo, pero que a la vez temía que esa idea fuese sólo una ilusión. Era apremiante, pues, luchar para evitar cualquier riesgo: si el destino no venía por sí mismo, había que forzarlo a venir.

No es extraño, pues, que Ursúa, quien había vivido en carne propia las ideas que buscaban alejar a la mujer de la ciencia, representase al feminismo como una lucha y llamase a sus lectoras a empuñar las armas del saber. ${ }^{78}$ Metáfora iluminadora que representa al conocimiento como una herramienta para matar, e ilustra muy bien el hecho de que para varias de las ensayistas el conocimiento era poder, en el más puro sentido baconiano. Por eso, Gimeno de Flaquer abogaba por que se armase al movimiento, forjando una nueva ciencia a la cual llamaba feminología, ${ }^{79}$ pues había que empezar "conociéndose a una misma”. Wright coincidía con esta visión, cuando escribía que llevaría a su hija a donde quiera que se estudiase el vicio para que aprendiera a combatirlo. ${ }^{80}$ El estudio, incluso de las cosas más rancias, resultaba libertador.

Para Wright, la educación que permitiera el desempeño laboral era la más urgente, pues la dependencia económica era la principal causa de la subordinación que enfrentaban muchas mujeres. En una metáfora reveladora, explicaba que una mujer desempleada ocupaba en su hogar el lugar intermedio entre el amo y el perro. ${ }^{81}$ La misma María Patiño, defensora de la bonanza medieval, concedía que en algún aspecto había habido avance, ya

${ }^{75}$ La Redacción (1904, enero). Memoria.

${ }^{76}$ Wright (1907c, octubre). Los libros. La Mujer Mexicana, pp. 1-2

${ }^{77}$ Wright (1905f, noviembre). La mujer contemporánea (primera parte)...

${ }^{78}$ Ursúa (1907b, agosto). 25 de agosto...

79 "La feminología o ciencia filosófica de la mujer, es la historia del sexo femenino, manifestando la representación que ha tenido en todos los periodos y épocas, tanto en la religión como en la ley, la poesía, el arte y la vida sexual. Entrañarían sus estudios la crítica comparativa entre la mujer y la hembra, los distintos caracteres que han presentado el sexo femenino en cada periodo de evolución progresista, la psicología de las mujeres que más hayan sobresalido en las virtudes, la ciencia, el patriotismo, las letras, las artes y la industria, y sobre todo el panegírico de las madres que cumplieron más perfectamente la misión de crear grandes hombres". Gimeno de Flaquer (1904, octubre). Feminismo. Memoria...

${ }^{80}$ Wright (1906c, febrero). La mujer inexperta. La Mujer Mexicana, pp. 1-2.

${ }^{81}$ Wright (1905a, enero). La mujer digna... 
que la mujer contemporánea, si bien ya no disfrutaba galanterías, al menos podía ser útil a su propio bienestar. ${ }^{82}$

No debe creerse, por ello, que sería responsabilidad de ambos sexos encargarse de las faenas del hogar, ni mucho menos. "Patria, Ciencia y Hogar" era el lema de la Sociedad Protectora de la Mujer. ${ }^{83}$ La administración de la casa y el cuidado de los hijos fueron las constantes alrededor de las cuales giró la defensa de la educación femenina. Orcillés, por ejemplo, suponía que, casada, debía dedicarse exclusivamente al hogar, su "esfera natural", ${ }^{84}$ mientras que otras feministas, como Wright, creían que la mujer en matrimonio debía ir más allá de aquél, sin desatender a su familia. ${ }^{85}$ Para ella, una mujer educada era la compañera más completa que podía desear un varón: le podría confiar intereses y proyectos, y entregar con seguridad la dirección del hogar. ${ }^{86}$ Es posible que algunas autoras, como Orcillés, creyeran profundamente estos argumentos, mientras que otras los usaran obedeciendo a una lógica táctica: exigían a la sociedad aquello que ésta pudiera estar dispuesta a ceder.

Eso sí, parece haber un gran consenso en torno a la idea de que la mujer que no quisiese casarse debía tener derecho a la instrucción y a mantenerse a sí misma. Para Wright, la mujer era libre de no casarse, si no encontraba un esposo que la respetara, ${ }^{87}$ cosa con la que por fin podía concordar con Trinidad Orcillés, quien advertía, sin embargo, que una vez que decidiera contraer matrimonio, tenía que someterse a las reglas del hogar. ${ }^{88}$ No es coincidencia que tres de las primeras médicas de la ciudad: Matilde Montoya, Columbia Rivera y Antonia Ursúa, nunca se hayan casado ni procreado (Cano, 2000, p. 239). La creencia sostenida en la libertad de la mujer a no casarse y centrarse en su vida profesional fue una coincidencia importante, entre varios desacuerdos. A fin de cuentas, todas eran feministas a su estilo.

\section{CONCLUSIÓN: UNA REVISTA, MÚLTIPLES DISCURSOS FEMINISTAS}

A lo largo de este trabajo, he tratado de demostrar que en La Mujer Mexicana convergieron distintas formas de comprender el feminismo, los feminismos que incluso pueden llegar a no parecer tales, porque como hoy los entendemos, no existían en aquel entonces. Los

\footnotetext{
${ }^{82}$ Patiño Suárez (1904, mayo). Trabajo leído en la sociedad La Elocuencia...

${ }^{83}$ Aróstegui (1905a, marzo). A la Sociedad Protectora de la Mujer en su velada inaugural. La Mujer Mexicana, pp. 3-4.

${ }^{84}$ Orcillés (1907c, junio). La mujer en su esfera...

${ }^{85}$ Wright (1905e, octubre). La emancipación de la mujer por medio del estudio (cuarta parte)..., pp. 1-2.

${ }^{86}$ Wright (1905e, octubre). La emancipación de la mujer...

${ }^{87}$ Wright (1907a, febrero). La mujer esposa. La mujer de México, pp. 1-2.

88 Las ideas de Orcillés estaban en sintonía con las de políticos influyentes y liberales de la época, como Justo Sierra y Ezequiel Chávez (Cano, 2000, p. 208). Orcillés, T. (1904, abril 2). Algo que importa. La Mujer Mexicana. 1(3), pp. 4-5. 
conceptos e ideas, como ha enseñado Joan Scott, son fruto de procesos históricos: no tienen una existencia suprahistórica, sino particular a cada momento. Además, como su evolución no es teleológica, hay que prestar atención a las distintas ideas en pugna, pues entonces no se sabía cuál prevalecería.

Así, hallamos que algunas mujeres apoyaban el feminismo en vagas nociones naturalistas de tipo determinista, aunque fueron ciertamente escasas. La enorme mayoría de las autoras parecen haber mantenido una concepción de la naturaleza, como ente maleable, acorde con la visión liberal y que abría las puertas a la convicción de que la instrucción de las masas podía crear mejores sociedades.

También vimos que el concepto de ciencia de estas autoras estaba fuertemente ligado a las artes; en cierto modo, ambas actividades formaban un solo conjunto coherente. En ocasiones, sin embargo, la ciencia era vista como una actividad que debía subordinarse a la autoridad de la religión e incapaz de llegar a verdades morales por sí misma; una visión que contrastaba tajantemente con otra, anticlerical de corte liberal, que depositaba su fe en el progreso de las ciencias y las artes. En el punto intermedio, una gama variable de arraigos hacia la ciencia y la religión era posible, en gran parte sustentada en la división positivista del mundo en fenómenos, perceptibles y conocibles, y noúmenos, sobre los que nada se podía aseverar sin caer en la especulación.

Encontramos discusiones en las que el feminismo halló sustento tanto en la religión como en la ciencia, aunque parece ser que el feminismo basado en la ciencia fue más transgresor que el que se amparó en la religión. Estos cimientos jugaron un papel trascendental a la hora de reconstruir y conceptualizar el papel de la mujer en el pasado, especialmente en el medievo y, a partir de allí, el rol que ésta debía desempeñar en la sociedad contemporánea. A pesar de estas diferencias, en mi opinión, sería incorrecto catalogar al feminismo de corte religioso/ortodoxo como conservador, pues me cuesta trabajo conceptuar un feminismo no disruptivo, aunque lo fuese tímidamente.

En suma, puedo concluir que el feminismo de La Mujer Mexicana, con toda su diversidad, giró en torno a la idea de que la mujer era libre de casarse o no, y debía tener el derecho a recibir educación para valerse por sí misma. Sin embargo, una vez casada, tendría que hacerse cargo de la educación de los hijos y de la administración del hogar. Si la mujer casada debía o no continuar trabajando, eso fue motivo de controversia. En cuanto las feministas asumían el papel de madres que la sociedad tradicional esperaba de ellas, también usaron esta conceptualización de la diferencia sexual para abogar por mejor educación y oportunidades laborales. La sociedad abría para ellas las puertas del magisterio, aunque muchas de las escritoras veían las labores científicas como las más prestigiosas a su alcance, 
pese a que su participación en ellas se enfrentase al rechazo de buena parte del cúmulo social.

Espero que este ejercicio sirva como muestra del valor de estudiar la diversidad en las publicaciones del pasado. Aunque muchas revistas decimonónicas y del siglo XX tuvieron líneas editoriales muy marcadas, otras fueron más abiertas al diálogo, si se atendía a un marco general de común acuerdo. En el caso que hemos visto, el marco fue el feminismo. Todo en La Mujer Mexicana giró en torno a él, pero lo hizo de manera heterogénea y plural. Prestar atención a los debates internos que aparecen en sus páginas y a sus múltiples proposiciones discursivas, enseña mucho sobre las preocupaciones de las feministas del porfiriato tardío y de las discusiones al interior de su movimiento.

\section{REFERENCIAS}

Alvarado, M. L. (2016). Laureana Wright: vida y pensamiento. En AlvaradO, L. (Ed.), Educación y superación femenina en el siglo XIX: dos ensayos de Laureana Wright. México: Universidad Nacional Autónoma de México (UNAM).

Alvarado, M. L. (2015). Alas para volar. Vida y obra de Dolores Correa y Zapata, Maestra Excepcional (1853-1924). En INFANTE VARGAS, L. (Ed.), Las maestras de México (pp. 47-80). México: Instituto Nacional de Estudios Históricos de las Revoluciones de México (INEHRM), Secretaría de Educación Pública (SEP).

Arteaga Castillo, B. (2005). La escuela racionalista de Yucatán. Una experiencia anarquista (1915-1923). México: Universidad Pedagógica Nacional.

BazAnT, M. (2015). Laura Méndez de Cuenca "gloria de su sexo". En Infante Vargas L. (Ed.), Las maestras de México (pp. 89-135). México: INEHRM, SEP.

CAnO, G. (2012). Ansiedades de género en México frente al ingreso de las mujeres a las profesiones de Medicina y Jurisprudencia. En Projeto História, 45, pp. 3-28.

CANO, G. (2000). Género y construcción cultural de las profesiones durante el porfiriato: magisterio, jurisprudencia, medicina y odontología. Historia y Grafía, 12, pp. 207-243.

CAnO, G. (1996). Más de un siglo de feminismo en México. Debate feminista, 14, pp. 345360.

Comte, A. (1875 [1842]). Principios de filosofía positiva. Santiago: Imprenta de la librería del Mercurio.

Collingwood, R. (2011 [1046]). Idea de historia, México: Fondo de Cultura Económica (FCE). 
DAMPIER, W. C. (2008 [1875]). Historia de las ciencias y de sus relaciones con la filosofía y la religión. Madrid: Tecnos.

ElEnA, A. (1985). Las quimeras de Las quimeras de los cielos. Aspectos epistemológicos de la revolución copernicana. Madrid: Siglo XXI Editores.

FRICKER, M. (1998). Rational Authority and Social Power: Towards a Truly Social Epistemology. Proceedings of the Aristotelian Society, New Series, 98, pp. 159-177.

HERNÁNDEZ CARBALlido, E. (2012). Periódicos pioneros fundados por mujeres: Las hijas del Anáhuac, El álbum de la mujer, El correo de las señoras y violetas del Anáhuac (1873-1889). Derecho a comunicar, 6, pp. 5-20.

INFANTE VARGAS, L. (2009). De la escritura al margen a la dirección de empresas culturales: Mujeres en la prensa literaria mexicana del siglo XIX (1805-1907). Tesis de Doctorado en Historia. México: UNAM.

INFANTE VARGAS, L. (2004). De Espíritus, mujeres e igualdad: Laureana Wright y el espiritismo kardeciano en el México finisecular. En TERraZAS, M. y CASTRO, F. (Eds.), Disidencia y disidentes en la Historia de México: UNAM-IIH.

KARDEC, A. (2008 [1857]). El libro de los espíritus. Brasilia: Consejo Espírita Internacional,

KOHN-BRAmSTEDT, E. (1961). La sociedad y el pensamiento político en Francia. En MAYER, J. P. (Ed.), Trayectoria del pensamiento político (pp. 146-186), México: FCE.

Larios GuZmán, M. E. \& Hernández Orozco, G. (2011). La Sociedad Filomática en Chihuahua. Síntesis. Revista de difusión de la Universidad Autónoma de Chihuahua, 8(18).

LÓPEZ BELTRÁN, C. (2002). De perfeccionar el cuerpo a limpiar la raza: sobre la sangre y la herencia (1750-1870). Relaciones, 99, pp. 235-299.

Martín Orozco, M. (2005). La Mujer Mexicana (1904-1906), una revista de época. Ethos educativo, 33, pp. 66-88.

Mejía MaCiLla, L. (2016). Empoderamiento femenino a través de La Mujer Mexicana a finales del siglo XIX y principios del XX. Anuario de Historia de la Educación, 17(2), pp. 158-172.

NeEDHAm, J. (1977). La gran titulación. Ciencia y sociedad en oriente y occidente. Madrid: Alianza Editorial.

Perrot, M. (2008). "Mi" historia de las Mujeres. Buenos Aires: FCE.

Rodríguez de Romo, A. C. \& CASTAÑeda LÓPEZ, G. (2012). La incorporación de las primeras médicas a agrupaciones científicas, académicas y sociales. Signos históricos, 28 , pp. 10-42. 
SCOTT, J. W. (1992) El problema de la invisibilidad. En RAMOS ESCANDÓN, C. (Ed.), Género e historia en México (pp. 38-65). México: Instituto Mora, Universidad Autónoma Metropolitana.

SCOTT, J. W. (2008). Género e Historia. México: FCE, UNAM.

SCHIEBINGER, L. (2004). ¿Tiene sexo la mente? Madrid: Ediciones Cátedra, Universidad de Valencia.

Solís Santos, C. \& Sellés García, M. (2013). Historia de la ciencia. Barcelona: Espasa Forum.

Torres Aguilar, M. \& Villegas, R. Y. (2015). La educación de la mujer mexicana en la prensa femenina durante el Porfiriato. Historia Educativa Latinoamericana, 17(24), pp. 217-242.

VALles Ruiz, R. M. (2019). La transición: de la educación a la emancipación. La Mujer Mexicana y Mujer Modernista. En Rivera Gómez, E., Tirado Villegas, G. A. \& García García, A. M. S. (Eds.), De las rebeliones a los movimientos sociales. Memoria, trayectorias y fuentes sobre la participación de las mujeres en México (pp. 95-101). Xalapa: Universidad Veracruzana.

VAlEnCIA Flores, A. (2013). Debate en torno a la enseñanza de la lógica en 1880: una experiencia histórica. Innovación educativa, 13(63), pp. 41-60.

VIESCA, C. \& SANFilippo, J. (2009). Las ciencias en el México independiente. En PÉreZ TAmayo, R. (Ed.), Historia de la ciencia en México (pp. 57-109). México: FCE, Consejo Nacional para la Cultura y las Artes.

White, A. (2009 [1896]). A history of the Warfare between Science and Theology in Christdom, vol. 1. Nueva York: Cambridge University Press.

\section{ACERVOS HEMEROGRÁFICOS}

Biblioteca Yucatanense

Hemeroteca Nacional 